\title{
Sistema Regional de Inovação: uma análise sobre os estados do Pará e do Amazonas
}

\section{Introdução}

Arthur Phillip Alberth Marques Da Costa1 (PPGE/UFPA)

Hilder André Bezerra Farias² (PPGE/UFPA) Márcia Jucá Teixeira Diniz ${ }^{3}$ (PPGE/UFPA

A economia mundial está cada vez mais baseada na produção e distribuição de conhecimento (LASTRES, 1999; CASSIOLATO e LASTRES, 2000; ETZKOWITZ E ZHOU, 2017). Assim, a produção torna-se dependente de uma cultura inovadora e vantagens relacionadas a infraestrutura de pesquisa e mão de obra qualificada (COOKE et al; 1996). A eficiência do quadro institucional reflete, e é reflexo das desigualdades e heterogeneidades entre países e regiões (DINIZ, 2005), de forma que o processo colaborativo entre os agentes, permite que as regiões se transformem em espaços onde se "aprende a aprender" (WOLF, S/D). Nesses espaços, o fluxo de conhecimento tácito é incentivado pelo compartilhamento de valores em comum, incentivando, assim, a inovação, o empreendedorismo e o desenvolvimento regional (STORPER, 1996).

Nesse sentido, a competitividade de uma região está na interação entre estruturas e atores, que pode resultar em oportunidades criativas para o desenvolvimento endógeno (ETZKOWITZ e RANGA, 2010). A luz desse entendimento a abordagem Hélice Tríplice sugere alianças sinérgicas entre universidade, indústria e governo com o intuito de estimular atividades de inovação e empreendedorismo, visando desenvolver novas estruturas de governança, baseadas nas especificidades regionais que geram vantagens competitivas e induzem a eficiência tecnológica dessas regiões (ETZKOWITZ e ZHOU, 2017).

A trajetória do Brasil nos últimos anos, assim como de outros países da América Latina, reproduz os modelos de produção dos países industrializados dentro de um contexto distinto do processo cumulativo de industrialização, esperando com isso, um resultado igualmente satisfatório ao dos países desenvolvidos (CASSIOLATO e LASTRES, 2000). Assim, o Brasil sem conseguir estabelecer um ambiente institucional favorável para o progresso tecnológico, os efeitos dessa estratégia, dentre outros resultados, concentraram ainda mais a estrutura industrial e tecnológicas

\footnotetext{
${ }^{1}$ Mestrando em Economia pelo Programa de Pós-Graduação em Economia (PPGE) da Universidade Federal do Pará (UFPA). e-mail: arthurecon2011@gmail.com.

${ }^{2}$ Orientador de mestrado do primeiro autor, professor do Programa de Pós-Graduação em Economia (PPGE) da Universidade Federal do Pará (UFPA).

${ }^{3}$ Coorientadora de mestrado do primeiro autor, professora do Programa de Pós-Graduação em Economia (PPGE) da Universidade Federal do Pará (UFPA).
} 
em poucas regiões resultando em agravamento das desigualdades regionais no país (STORPER, 1996).

Posto isto, este presente trabalho objetiva descrever o Sistemas de Inovação dos estados Pará (PA) e do Amazonas (AM), caracterizada na estratégia de interação entre as firmas e com outros agentes. $O$ texto foi construído da seguinte forma: além desta introdução, o item 2 resgata os principais conceitos da literatura sobre inovação a partir das construções teóricas Schumpeteriana, Evolucionária e Neoinstitucionalista; o item 3 debate a construção de um ambiente institucional favorável para inovação a partir dos conceitos de SNI, SRI e do modelo hélice tríplice a construção; e o item 4 apresenta um resgate da experiência brasileira no desenvolvimento de políticas de estímulos, concentração da estrutura de científica do país refletindo na formação do seu SI. Em seguida apresenta-se o debate sobre o ambiente interno e externo as firmas, com dados retirados da PINTEC contendo o Sls do AM e PA. E por fim, o item 5 resume as principais conclusões do artigo e futuras perspectivas.

\section{Revisão da Literatura}

O processo de inovação é marcado pela dinamicidade e acelerada incorporação de novos conhecimentos nos produtos manufaturados e na gestão organizacional. Esse processo, está diretamente relacionado a disseminação, armazenamento e processamento de enormes quantidades de informações codificadas, enraizadas em organizações, pessoas e locais (NELSON; WINTER, 2005; LASTRES; ALBAGLI, 2002).

As mudanças introduzidas pela sociedade baseada no conhecimento (DINIZ, 2005) tem caráter bastante amplo, porém, refletem a desigualdade na geração e internalização do conhecimento, adoção de novas práticas de produção, comercialização e o consumo de bens e serviços além de vantagens competitivas regionais (DOLOREUX E PARTO, 2005). Ou melhor, as vantagens que estavam, quase que restritamente, baseadas nos efeitos da escala de produção (competitividade/preço) (CONTI, 2005) sobre o nível de competitividade, ganham múltiplas dimensões. Em linha geral, não basta que o conhecimento possa ser disseminado por meio de produtos ou serviços, mas é necessário a capacidade de codificar o conhecimento, baseado na capacidade de aprendizado, acúmulo e rotinas (LASTRES; ALBAGLI, 2002; CONTI, 2005).

Para a Teoria Evolucionária a causa do desenvolvimento econômico advém do nível de competitividade que as firmas adquirem com a capacidade de criar novos produtos, novas formas de fazê-lo ou novas combinações de fatores produtivos (LUNDVALL, 1992). Essa capacidade de transformação seria uma ação específica, sendo que seus resultados carregam diferentes graus de incerteza, pois dependem de formatos organizacionais que estimulem os processos de aprendizagem e, consequentemente, da capacidade tecnológica das empresas. Logo, as firmas, 
teriam em sua forma genética uma dinâmica que impõe a necessidade de um processo de inovação contínuo, seja por meio de adaptação ou pela busca de liderança do processo tecnológico. Assim, o nível de competitividade reside no desempenho das firmas e, por conseguinte a sua permanência ou não no mercado (FERRAZ et tal, 1995), uma vez que, em um ambiente onde todas as firmas têm o mesmo propósito, o de se manterem aptas, o mercado tornase altamente seletivo, evidenciando a busca pela melhor performance de cada firma (NELSON e WINTER, 2005).

\subsection{A Nova Economia Institucionalista}

A inovação é um processo evolutivo de aprendizado coletivo (COOKE et al.1996) resultante da colaboração de muitos atores e fatores, tanto internos quanto externos as firmas (DOSI 1982, EDQUIST, 2006). Essas ações determinam as perspectivas e evolução das instituições responsáveis pela regularização e pela regulamentação do "comportamento econômico". (MEYER; ROWAN, 1977; ASHEIM e HERSTAD, 2005). Segundo Coase (2008), as instituições têm relevância para o ambiente econômico, no qual a divisão do trabalho obriga os agentes a transacionar seus produtos no mercado, sendo 0 ato de troca mediado por regras que ajudam a reduzir as incertezas e dar maior eficiência as negociações procurando a proposta mais vantajosa arbitrando a colaboração e conflito (FIANI, 2011).

Os trabalhos associados a Ronald Coase, Oliver Williamson e Douglass North compartilham de conceitos que fundamentam a NEl, baseando-se na transação como unidade básica de estudo e questionando como as instituições afetam a eficiência produtiva e que a escolha da coordenação do processo produtivo deve implicar no menor custo de transação, e ao modelo de governança mais eficiente (mercado ou hierarquia) para resolvê-las (FIANI, 2011).

Com seus estudos Coase (1937, apud FIANI, 2011) deparou-se com dois tipos de organização responsável pela produção, o mercado e as empresas. O mercado, é onde ocorrem as negociações contratuais para a aquisição de bens por meio dos sistemas de preços, e a outra seria empresa, compondo o mercado, sendo que, essas são responsáveis pela estrutura hierárquica de produção. 0 intuito era destacar que haveria custos que não eram incorporados a produção, mas, estariam relacionados a necessidade de transacionar, ou seja, havia "custos para usar o mecanismo de preços" (COASE, 2008).

Assim, a preocupação de Coase (2008) está no fato de que diferentes instituições implicam em diferentes custos de transação, e, que as empresas escolham no mercado as oportunidades que garantem o menor custo, caso contrário, essa troca não ocorreria no mercado. Essa escolha se faz presente no atual processo de inovação dinâmica, onde há necessidade de 
adquirir conhecimento complementares as capacidades de aprendizado que a firmas possui, implicando em interação com outras organizações e custos transacionais (HERSTAD, 2003).

Os custos de transação orientam as firmas na escolha para a estrutura de governança que apresente os melhores resultados (WILLIAMSON, 2008). Na tentativa de agregar o elemento temporal na relação contratual, Williamson (2008), discrimina os custos de transação em custos de transação ex-ante e custos de transação ex-post com os atributos presentes em cada transação para determinar a escolha das estruturas de governança que indique os menores custos, seja pelo mercado ou pela internalização do processo. À medida que os contratos firmados não conseguirem antecipar as incertezas provenientes dessas transações, torna-se eminente a reestruturação das transações que já estão em curso, e a adaptação eficiente dos agentes nos contratos futuros inibindo os ganhos oportunista.

Segundo Williamson (2008), as trocas econômicas são baseadas em racionalidade limitada e o poder de barganha, compostas por incertezas e complexidades, em especial quando as transações envolvem ativos específicos. As firmas inovadoras tornam-se competitivas ao desenvolverem e controlarem competências por meio de conhecimento tácito, um ativo específico e intransferível das organizações individuais (HERSTAD, 2003). Analisando a partir da dinamicidade das inovações e suas possíveis mudanças, os custos de transações presentes e futuros serão afetados, e nos limites do ambiente institucional, uma nova configuração da governança específica e operacionalizada (FARINA et al, 1997).

Williamson (2008) tem como objeto de estudo a relações entre as estruturas de governança e a eficiência nas transações contratuais, focando em uma análise micro institucional. Já outra linha complementar a essa, analisa todo o complexo social existentes. Essa visão está sob a ótica macro, relacionado o funcionamento das instituições ao crescimento econômico, destacando as instituições como as "regras do jogo" (NORTH, 1990), logo o seu foco está voltado para a construção e as mudanças do ambiente institucional, tendo Douglass North seu principal defensor.

Para Douglass North (1990) as instituições seriam responsáveis pela manutenção das "convenções", a partir de acordos informais, tais como as tradições, os costumes e os códigos de conduta e estruturação das "leis" (as regras oficiais) voltadas ao aperfeiçoamento das relações entre os indivíduos, atuando de modo a minimizar as incertezas que são internas as transações e acabam por prejudicar o ambiente econômico.

Nesta perspectiva, North (1990) analisa a evolução das instituições e, como a matriz institucional afeta o crescimento de longo prazo. Assim, o seu direcionamento para o estudo dos custos de transação são os custos de enforcement, relacionados ao cumprimento dos contratos, 
e a presença forte do Estado coercitivo, e os custos de measurement, que estão relacionados a redução das incertezas e a racionalidade limitada dos agentes. Quem? Enfatiza a dimensão histórica da interação entre as instituições e as organizações, o primeiro enquanto regra do jogo e o segundo enquanto jogador destacando, o viés evolucionário das mudanças institucionais, permitindo identificar o caráter das trajetórias históricas das instituições, incorridos da influência de fatos históricos vivenciados na evolução institucional (HERSTAD, 2003).

Esse relacionamento entre agentes, aqui tratado a partir de convenções, sustentam a abordagem dos Sistemas de Inovação e suas variantes, como o Sistema Regional de Inovação que destaca as instituições informais fortalecida por relações de confiança e reciprocidades que se transforma em vantagens competitivas para as regiões (ASHEIM et al, 2019).

\section{Inovação}

Os debates sobre inovação ganham maior visibilidade com o trabalho de Schumpeter (1984). Ele definiu como inovação a realização de novas combinações nos processos de produção ou organizacionais podendo ser realizadas por meio de: 1) inovação em produtos; 2) inovação em processos; 3) uma nova organização de mercado; 4) abertura de novos mercados e por fim 5) uma nova fonte de matéria prima.

Ao destacar a inovação como motor da economia capitalista, Schumpeter (1984) centrouse na figura do empresário inovador como o agente que seria capaz de estimular o progresso tecnológico por meio do processo de "destruição criadora", sendo um fator fundamental na sociedade capitalista. $\mathrm{O}$ ambiente inovativo seria acrescido de outro fator de extrema importância, o sistema de crédito, uma vez que, segundo o autor, estes dois elementos seriam responsáveis pelo sucesso do processo de inovação. Tais elementos seriam, o empresário enquanto a gente competente para a gestão do processo inovador e, o outro como intermediário com os recursos financeiro necessários.

Contudo, a busca de maior compreensão para processo de inovação, incorreu em novas contribuições para o tema, uma vez que a visão linear sofreu questionamentos sob a complexa trajetória entre as ações realizadas na estância científica e tecnológica até chegar ao mercado (LASTRES; ALBAGLI, 2002). Dessa forma, agregou-se na análise a relação entre 0 ambiente econômico e as direções das mudanças tecnológicas, como interdependentes, irregulares e imprecisas, influenciadoras das trajetórias e rotinas das firmas inovadoras (DOSI, 2006; LASTRES; ALBAGLI, 2002; NELSON E WINTER, 2005).

Dentro do arcabouço teórico de Schumpeter, muitos autores começaram a debater sobre a inovação como impulsionadora do crescimento e desenvolvimento econômico dos países. Em 
sua análise, Schumpeter já determinava o caráter evolucionário da economia capitalista, uma vez que, seus estudos objetivaram a dinâmica interna deste, como explicação do desenvolvimento gradual e progressivo (PAIVA et tal, 2018). A Teoria Evolucionária representa uma forte contribuição dos neochumpeterianos para o debate, partindo do fato que, o processo evolutivo é a constatação que os organismos compartilham ancestrais comuns e ambos os indivíduos estão unidos por relações históricas - não tendo origens independentes - mas, sendo parte de um todo que envolve um processo sucessivas diversificações.

Os evolucionários caracterizam a inovação como um processo interativo e sistêmico, dependente do ambiente institucional, da interação entre as diferentes etapas e torna-se resultado da contribuição multidisciplinar de diferentes agentes, internos e externa as firmas (ASHEIM et al, 2019).Essa corrente teórica teve início na década de 70, com a contribuição de diversos autores como Richard Nelson e Sidney Winter, Giovanni Dosi, entre outros. As discussões sobre a teoria evolucionária do crescimento econômico debate questões tais como: rotinas, cumulatividade, habilidades, conhecimentos tácitos e escolhas das firmas, renegados nos debates pela teoria ortodoxa.

Para a Teoria Evolucionária, a capacidade técnica é uma variável endógena, sendo resultado das regras de decisão dos agentes econômicos, como o objetivo de reduzir as incertezas do processo produtivo. As rotinas são padrões de regularidades desenvolvidos pelas firmas, acumulados a partir de processos dinâmico adquirido por condições históricas anteriores. Esses padrões comportamentais são representados por habilidades adquiridas, à medida que, são produzidos por cumulatividade, conhecimento ou contextos já vivenciados, reduzido os custos de transação e servindo como parâmetros para a sua tomada de decisão em um ambiente competitivo e de extrema incerteza (DOSI, 1982,2005; ARTHUR, 1989 ; NELSON e WINTER, 2005; EDQUIST, 2006).

$\mathrm{Na}$ visão de Arthur (1989) o processo de novas tecnologias é constituído de bases tecnológicas já criadas, resultando da competição entre as tecnologias já existentes e as tecnologias emergentes. Essa junção entre o passado e presente tecnológico determinará 0 alinhamento da atividade tecnológica aplicada, impulsionando as trajetórias reais em detrimento das trajetórias possíveis. Esse conflito condiciona a desigualdade entre as firmas como consequência dos diferentes regimes tecnológicos (BRESCHI e MALERBA, 1997), afetando o desempenho da firma e a dinamicidade do mercado. O nível mais alto de desenvolvimento da trajetória tecnológica é definido como "fronteira tecnológica", estando ligado a todo esse conjunto dos conhecimentos tecnológicos (MALERBA, 2002; DOSI, 2005). 
Essa desigualdade cria as oportunidades tecnológicas que poderão ser aplicadas dependendo da estratégia de crescimento de cada firma. As firmas buscam estabelecer suas estratégias, com base na análise minuciosa do mercado em que se encontram, conhecendo a natureza das barreiras à entrada, das regulações do mercado e do grau de competitividade (FERRAZ et al, 1995). Freeman e Soete (2008) evidenciam que as empresas avaliam dentre uma série de opções e estratégias que se demonstrem mais especializadas para firma, considerando alguns critérios como sua estrutura interna de P\&D, suas habilidades, seus recursos científicos e técnicos, haverá possíveis combinações de escolha, já que sua estratégia é afetada pelo seu processo de cumulatividade.

Esses autores destacam ainda, que existem seis tipos de estratégias que as firmas podem adotar, dependendo da capacidade técnicas pelas empresas. A capacidade tecnológica das firmas está vinculada a sua estratégia e nível de governança em que a firma optou operar, compreendendo como os recursos, conhecimentos e tecnologias serão alocados resultando na performance da empresa, assim, a estratégia de mercado é acoplada com a estratégia tecnológica que em que cada firma opera (FREEMAN E SOETE, 2008). Segundo os autores, as estratégias podem conforme descrito no Quadro 1.

Quadro 1- Estratégias das Firmas

\begin{tabular}{|c|c|c|}
\hline NOME & ESTRATÉGIA & RESULTADOS /OBJETIVOS \\
\hline Ofensiva & Inovações em produtos. & $\begin{array}{c}\text { A empresa escolhe liderar o processo } \\
\text { tecnológico e conquistar novas fatias de } \\
\text { mercado. }\end{array}$ \\
\hline Defensiva & Inovação incremental & $\begin{array}{c}\text { A competitividade dessas empresas está em } \\
\text { criar condições de absorver as mudanças } \\
\text { tecnológicas e desenvolver competências no } \\
\text { setor de P\&D; }\end{array}$ \\
\hline Imitativa & Saber fazer o produto & $\begin{array}{l}\text { Apenas seguem as tendências de outras firmas } \\
\text { líderes, seu know how está na massificação da } \\
\text { produção; }\end{array}$ \\
\hline Dependente & $\begin{array}{l}\text { Atendimento de seus } \\
\text { pedidos }\end{array}$ & $\begin{array}{l}\text { O processo tecnológico é direcionado para } \\
\text { garantir o funcionamento da firma matriz; }\end{array}$ \\
\hline Tradicional & $\begin{array}{c}\text { Não demanda } \\
\text { inovações, uma vez que, } \\
\text { a concorrência é amena. }\end{array}$ & $\begin{array}{l}\text { As mudanças tecnológicas são lentas, gerando } \\
\text { pouca variação tecnológica nos produtos; }\end{array}$ \\
\hline Oportunista & $\begin{array}{l}\text { Utilizar tecnologia } \\
\text { adquirida }\end{array}$ & $\begin{array}{l}\text { Essa firma identifica oportunidades em } \\
\text { mercados, ainda pouco explorados. }\end{array}$ \\
\hline
\end{tabular}

Fonte: Freeman e Soete, (2009) adaptado.

Assim, as estratégias das firmas também são resultado da sua eficiência ao longo de sua trajetória, tornando-se ativos específicos de cada empresa, não sendo possível ser copiadas ou 
transferidas. Igualmente, pode-se observar as diferenças entres trajetórias dos países ou regiões, relacionada a dinamicidade das instituições, e o desenvolvimento das relações de cooperação entres os agentes (DINIZ, 2005; FIANI, 2011). Essas relações enraizadas localmente, estabelecem redes inovadoras de cooperação e coordenação agindo como facilitadores do processo de inovação, tornando as empresas ou regiões espaços onde se "aprende a aprender" (DINIZ, 2005), estreitando parcerias com infraestruturas de pesquisa locais, fortalecendo os fluxo de conhecimento (ROBIN e SCHUBERT, 2013; NEGRI E SQUEFF, 2016; ETZKOWITZ, 2017) e dos atributos regionais (CONTI, 2015).

Segundo Etzkowitz (2017), a expansão dos relacionamentos por meio dessa união de esforços altera o modelo de governança, sobretudo no ambiente regional de inovação, pela regularidade e pela constância das transações econômicas entre as organizações ser facilitada em escala local. Desta forma, as universidades e centros de pesquisa locais também ganham com esses projetos construídos em conjunto com as empresas, gerando conhecimento, novos produtos e processos que incorrem no aumento das vantagens competitivas regionais (ROBIN e SCHUBERT, 2013).

Assim, a busca por inovação não é uma preocupação somente das firmas, uma vez que está presente nos debates de muitos países e regiões por ser uma variável chave para 0 crescimento econômico (FREEMAN, 1995; SUZIGAN e ALBUQUERQUE, 2011;), sendo resultado de um processo colaborativo, a exemplo das universidades e dos governos que tornam-se atores de extrema relevância para a construção de um ambiente propício à inovação (ETZKOWITZ, 2017).

\section{Sistema Nacional de Inovação}

Os debates sobre os "Sistemas Nacional de Inovação" (SNI) são um novo olhar para planejar o desenvolvimento a partir de relações econômicas baseadas no conhecimento e das capacidades endógenas de cada país. Uma abordagem na qual a inovação engloba a estrutura produtiva e o quadro institucional como ativos específicos de país para país, ativos esses que refletem em trajetórias constituída, determinando a escala, direção e sucesso de todas as atividades de inovação (LUNDVALL, 1992; NELSON, 1993) ajudando na análise das contradições entre os países desenvolvidos ou subdesenvolvidos (CASSIOLATO e LASTRES, 2005). Destacam-se os trabalhos de Chris Freeman (1987) e Richard Nelson (1988), com maior difusão no início dos anos 90, a partir da obra de Nelson (1993) a qual faz uma análise comparativa de entre SI de diferentes países. 
Freeman (1995) conceituou o sistema nacional de inovação como um conjunto de instituições, atores e mecanismos que cooperam para a implantação e difusão das inovações tecnológicas em um país. Destacam-se, entre esses agentes, os institutos de pesquisa, o sistema educacional, as firmas com seus setores de P\&D, as agências governamentais, a estrutura do sistema financeiro, as leis de propriedade intelectual e as universidades (ETZKOWITZ, 2017; SUZIGAN e ALBUQUERQUE, 2011). Albuquerque (1996) também contribui para o debate, afirmando que Sistema Nacional Inovação (SNI) é "uma construção institucional", onde há interface entre as instituições constituintes, a fim de, promover atividades planejadas e conscientes, que estimulem o progresso tecnológico nacional e otimizando as ações de cada ente, pelo fluxo de conhecimento existente (ETZKOWITZ, 2017).

Os Sls são sistemas abertos, o que conduz a definições e limites em sua abordagem são o objeto de estudo, os efeitos de novas especializações em uma região, bases de conhecimento de uma determinada tecnologia ou a evolução de um determinado setor produtivos (COOKE, 1996; CARLSSON et al 2002; ASHEIM, 2019). Quando se aborda a inovação como processo com contextualização social, cultural e institucional específicos, torna-se necessário uma definição mais restrita, focada nesses fatores que direcionam as atividades inovadoras explicitamente nas instituições de ciência e tecnologia (ASHEIM, 2019). A importância da aplicação de uma perspectiva de estudo a nível regional reside principalmente na importância da proximidade geográfica para o compartilhamento de conhecimento e aprendizado interativo, bem como no papel da região em um nível intermediário de governança. atividades econômicas relacionadas ou não relacionadas

O ambiente institucional é afetado por fatores econômicos, políticos e culturais que direcionam as atividades de inovação. Ao passo que, a estabilidade institucional é constituída pela governança e pela intensidade das interações entres os agentes, estabelecendo os padrões de cooperação e coordenação que facilitam o aprendizado (DINIZ, 2005).

Etzkowitz e Leydesdorff (1997) apontam que é estratégico para o SNI a relação sinérgica envolvendo três esferas institucionais distintas: i) as universidades e centros de pesquisa; ii) 0 governo; iii) e as empresas. Sendo as universidades responsáveis pelos avanços na pesquisa básica, o Estado como mediador financeiro e institucional e as empresas, responsáveis pela aplicação de conhecimento no sistema produtivo. Assim de forma geral, cabendo como base para competitividade do país e fortalecimento do SNI, a capacidade de interação entre esses agentes, a governança que passa a ser compartilhada entre os agentes o que acaba por possui uma conotação política, localizada e cumulativa do processo como um todo, em que a inovação depende aspectos institucionais (LUNDVALL, 1992), fortalecendo a especialização competitiva 
regional (DINIZ, 2005 ; STORPER, 1996; ETZKOWITZ, 2009) e fatores setoriais (MALERBA, 2002; ARCURI, 2016).

\section{Modelo Hélice Tríplice e a Sinergia Trilateral}

A análise da Hélice Tríplice tem como foco a universidade enquanto instituição norteadora do desenvolvimento regional, abordando como regiões emergem e novos regimes aparecem direcionando o desenvolvimento local (ETZKOWITZ E ZHOU, 2017). Assim, o modelo HT destaca a importância da institucionalização do empreendedorismo nas organizações, com destaque nas universidades, transformando-se em agente direto de transferência de tecnologia. Assim, a missão da universidade é ser empreendedora, realizando de maneira conjunta educação, pesquisa e desenvolvimento social, transformando a universidade em uma instituição de relevante atuação no novo modelo de produção, o qual as políticas de inovação se apresentam na capacidade de inovação organizacional e tecnológica.

Ainda que a universidade tenha a liderança, Etzkowitz (2009) destaca a importância do fortalecimento de cada hélice, à medida que as capacidades internas de cada instituição se desenvolvam, por meio do fortalecimento das relações bilaterais (e mediadas por uma terceira hélice), o que acarreta aumento do fluxo de conhecimento entre as esferas (ETZKOWITZ E ZHOU, 2017), tendo como base a coordenação da produção organizada de conhecimento em uma dada economia (baseada em conhecimento) (ETZKOWITZ E LEYDESDORFF, 1997).

O Governo é relevante em uma economia de hélice tríplice, atuando como incentivador das relações U-I, e também como capitalista de risco, garantindo uma aproximação entre capital privado e as iniciativas empreendedoras da universidade. $O$ papel do Governo se torna ainda mais relevante em locais que não possuam uma estrutura produtiva relevante, pois o mesmo precisa , reconhecer as capacidades locais e criar a base de conhecimento para permitir um ambiente favorável à implantação de novas empresas, o que faz com que estas ações se tornem a base de uma política industrial (ETZKOWITZ, 2009).

$O$ amadurecimento do modelo estimula o fluxo de conhecimento de uma esfera para outra como resultado da densidade da circulação de conhecimento, renovando as microestruturas e as macroestruturais do HT. Logo, o desempenho inovador manifesta-se em ganhos para toda sociedade, por meio da operacionalização e a implementação de políticas públicas de desenvolvimento regional, promovendo o desenvolvimento científico, tecnológico, e desenvolvimento autossustentável mediante a interação entre as três hélices. A seguir, expõemse alguns trabalhos que abordaram o Sistema de Inovação do Brasil. 


\section{Formação do Sistema Brasileiro}

Partindo desse resgate da trajetória econômica do Brasil, centraliza-se agora a análise no desenvolvimento do SI do Brasil e sua interface com os Sistema Regionais de Inovação (SRI). 0 SN do Brasil pode ser considerado em nível de construção intermediário(SUZIGAN e ALBUQUERQUE, 2011) tendo como característica a baixa mobilização de pesquisadores alocados nas unidades de ensino e pela baixa interação U-I, - exceto alguns setores no qual o ambiente institucional estimulou, o que garantiu a eles competência tecnológica - que acaba por enfraquecer 0 processo de retroalimentação entre a esfera científica e esfera tecnológica (SUZIGAN et al 2011, RAPINI et al. (2009). Esses autores citam como causa desse atraso, a criação tardia das Universidades, resultando na capacidade na industrialização tardia do país, e indicam ainda que estes eventos também são simultâneos ao desenvolvimento atrasado de instituições monetárias e financeiras.

Como foi apresentado durante este trabalho cada país apresenta uma configuração diferente para o seu SN, de maneira que essa diversificação tende a ser um reflexo do ambiente institucional construído ao longo de sua trajetória. Assim, o Sistema de Inovação (SI) brasileiro é uma construção das estratégias implementadas a partir do contexto histórico de vantagens tecnológicas e institucionais que foram projetadas de fora para dentro, em países industrializados com outro quadro institucional, em contraposição às questões tecnológicas e econômica que países da América Latina vivenciam desde do Processo de Substituição de Importação (PSI) (STORPER, 1996). No Brasil essa estratégia obteve resultados positivos no período que se estende de 1930 até a década 1970, com aumento elevação e diversificação da produção industrial e da participação da indústria na economia brasileira (STORPER, 1996; CASSIOLATO e LASTRES, 2000).

Este cenário relaciona-se com a trajetória tecnológica do Brasil, já que as empresas tomaram uma postura sem grande risco com importações de tecnologia, transferindo para 0 governo a responsabilidade de estimular a PSI, de forma que o setor público financiou e capacitou mão de obra nas instituições de ensino públicas, administrou os bancos de desenvolvimento e, por meio das estatais que tinham a maioria dos laboratórios de P\&D estimulou setores chaves, como telecomunicações, energia, aeronáutica, petróleo, aço e vários sistemas agroindustriais, dentre os quais são ponto de interação bem-sucedidos no país (CASSIOLATO e LASTRES, 2000).Porém, por acontecimentos externos e internos há perda de dinamismo da economia latino americanas na década de 80, com massiva transferência de recursos reais para 0 exterior, encerrando o ciclo de taxa de crescimento mais elevadas para economia, e o investimento perde a função impulsionadora do crescimento iniciando o período de baixa taxas e de grande 
volatilidade nas taxas de crescimento, o qual é impulsionado pela demanda. Nessa transição, entre a PSI para uma política de estímulo às exportações, o país amarga baixo crescimento, durante a década de 1980 e na primeira metade da seguinte, resultado de uma política fundamentada na abertura comercial e na desregulamentação dos mercados (CARNEIRO, 2008).

Esse período pós 1980 contrasta com a estratégia anterior e o modelo PSI, onde o país obteve resultados favoráveis em uma trajetória de crescimento que se assemelhava com os países desenvolvidos. Com o processo de globalização, o Brasil não obtém bons resultados, há perda de dinamismo industrial, sobretudo em segmentos que indústria apresentava boa performance. Essa perda de dinamismo ocorre como consequência de uma nova estratégia econômica para o país, cujo objetivo foi melhorar a competitividade da indústria para estimular as exportações. A abertura comercial visava a instalação de uma infraestrutura produtiva que pudesse permitir um salto no nível tecnológico do país, sendo que dentre os mecanismos adotouse 0 fim da proteção à indústria nacional com a desregulação dos Investimentos Diretos Estrangeiros (IDE). Outro ponto chave, foi a abertura financeira com o objetivo de ampliar a poupança externa e estimular a competitividade no setor bancário, para garantir redução dos custos do financiamento para a nova estrutura industrial. Ocorre também o enfraquecimento do Estado com as privatizações, e a perda de sua capacidade de estimular o crescimento e promover a equidade social (CARNEIRO, 2002; LAPLANE et tal, 2003).

A abertura econômica visava reproduzir as experiências de crescimento alcançados pelo Japão e a Coréia do Sul durante as décadas de 70 e 80, tendo como pilar os investimentos no desenvolvimento tecnológico de setores industriais dinâmicos. Esperava-se que as empresas estrangeiras liderassem 0 avanço tecnológico e produtivo em um modelo com destaque para as exportações semelhante aos países asiáticos, com maior especialização da base produtiva e maior conteúdo tecnológico (CURADO, 2013). Ao contrário do modelo asiático de crescimento, 0 modelo brasileiro foi voltado para o mercado interno, houve pouca diferenciação na estrutura produtiva, e uma especialização regressiva da estrutura produtiva industrial, com reduzido efeito sobre as exportações e ampliação das importações (LAPLANE et tal, 2003).

No início dos anos de 2000, o governo decide retomar a coordenação do processo de ciência e tecnologia alinhado com o sistema produtivo. Nas últimas décadas houve uma participação maior do governo brasileiro com ação em dois eixos, na estruturação de um ambiente institucional que permitisse a implementação de uma política para fortalecimento da ciência e tecnologia e que estimula o setor produtivo por meio de uma aproximação da relação U-I. E o outro eixo foi a implementação de mecanismos fiscais e creditícios estimulando a política de 
criação de fundo de financiamento tecnológico para setores chaves ${ }^{4}$ com o objetivo de reduzir os custos da inovação (CASSIOLATO et al, 2015).

No Brasil, nos últimos anos, o desenvolvimento do SNI, tende a ser analisado a partir da grande concentração de capacidade tecnológicas nas regiões Sul e Sudeste, desta forma análise do Sistema Setorial de Inovação (SSI) ou do Sistema Regional de Inovação (SRI) pode se aproximar a análise mais próxima da realidade (EDQUIST, 2006). Para Edquist (2006) o SSI é composto por um conjunto de empresas, em especial as privadas, atuando na geração e utilização de produtos com tecnologias inovadoras, elas interagem principalmente sob a forma de atividades de cooperação para a difusão de novas tecnologias, ou sob a forma do jogo de mercado e dos mecanismos de competição e seleção, sendo assim, o acúmulo de conhecimento tecnológico e a base de conhecimento são específicas para cada setor e são causa para dinamicidade das fronteiras tecnológicas (DUNHAM et al, 2011)

No que tange aos resultados alcançados pela política para fortalecimento da ciência e tecnologia, houve o fortalecimento de infraestrutura para pesquisa, de acordo com Miranda e Zucolota (2016) houve um avanço nas produtividades das instituições de pesquisa sendo analisada por meio do número de patentes produzidas. Esse avanço refletiu em melhorias na relação deste com o setor produtivo (CASSIOLATO et al, 2015).

\section{Sistema Regional de Inovação}

Como colocado, o nascimento e consolidação de Sistema Regional de Inovação (SRI) baseados na geração, uso e disseminação de conhecimento é o foco da do modelo hélice tríplice. Segundo Doloreux (2004) as definições são muito próximas entre os conceitos do SNI e SRI, semelhanças que inspiram debates ainda em desenvolvimento entre quais as definições seriam os limites conceituais de ambos.

Destaca-se como consenso no conceito do SRI a ideia de que o desenvolvimento inovativo é resultado da interação entre estruturas e atores que ocorrem dentro de um território capaz de criar, absorver e aperfeiçoar ativos específico baseado em aprendizado e conhecimento promover tanto os atores que produzem quanto os atores que absorvem inovação. (COOKE, 1996; CARLSSON et al 2002, DOLOREUX e PARTO, 2005; DINIZ, 2005).

Segundo Edquist (2006), os SRIs têm como principal argumento as diversidades entre as regiões que formam um país, possuindo suas construções institucionais próprias, com elementos

\footnotetext{
${ }^{4}$ Para saber mais sobre os fundos setoriais no Brasil http://www.finep.gov.br/ - Finep. 
históricos, sociais e produtivas bem definidas, diferentes umas das outras o qual é constituído de aspectos singulares aos seus SIs. Assim, foi desenvolvido, no início dos anos 1990 o conceito do SRI, baseado na articulação de arranjos, sistemas produtivos e recursos regionais que estimulam o desenvolvimento tecnológico e econômico a partir, da ampliação da capacidade de geração, da difusão e da utilização de novos conhecimentos em um processo que depende da contínua interação desses agentes locais, provocando efeito de spill-overes, capaz de proporcionar 0 desenvolvimento regional. (CASSIOLATO E LASTRES, 2000).

Cada vez mais o ambiente torna-se um fator determinante para o processo inovativo (DINIZ, 2005). Cassiolato e Lastres (2000) destacam que a localização é um fator relevante para as atividade de inovação, pois há significativa importância na aprendizagem localizada, e nas externalidades associadas à interação entre os atores locais e seus elemento de coesão, ou seja, sua estrutura institucional, sendo essa capacidade de interação, aspectos específicos para a competitividade regional.

A interação sistêmica resultante em um ambiente virtual nessas regiões que "aprende a aprender"(WOLF, S/D; DINIZ, 2005; STORPER, 1996, ETZKOWITZ, 2009) criar e recriar aprendizagens multidisciplinares estimulando soluções criativas para superar na medida em que possam ser superadas e, assim, criar um "espaço de competências a fim de reforçar capacidade inovadora e competitividade da região (GERTLER, 2003 apud DOLOREUX, 2004 ). Esse ambiente virtual é resultado do relacionamento das organizações, no caso do modelo hélice, e nas interfaces entre U- I -G onde ocorre o nascimento de competências capazes de sustentar um processo de desenvolvimento regional a partir de capacidades endógenas (Etzkowitz e Leydesdorff, 1997).

Assim, a exposição do modelo hélice tríplice, permite agregar os conceitos do SNI e SRI com a internalização de conhecimentos, aprendizagem e governança que formarão os fluxos que circularão entre as porosidades das instituições formando espaços de concessão, de conhecimento e de inovação que fomentam o desenvolvimento das regiões, dos setores produtivos além de estimular a interface entres as hélices, ampliando o alcance do aprendizado. Essas mudanças ocorrem, a partir do fortalecimento das atividades de empreendedorismos nas universidades e sua ascensão enquanto instituição primordial de desenvolvimento regional. Esse contexto teórico consolida um suporte para a análise sobre a formação do ambiente de inovação e como podemos analisar os casos dos Estados do Pará e Amazonas.

\section{Metodologia}


O Amazonas é maior estado do Brasil, possui a maior floresta tropical do mundo e tem 0 turismo como forte atividade econômica no estado. A instalação do Polo Industrial de Manaus (PIM), estimulou o desenvolvimento regional atraindo, por meio de incentivos fiscais, inúmeras empresas nacionais e internacionais a capital do Amazonas, sendo o turismo um forte estímulo para economia do estado. Já a economia paraense, se encontra mais diversificada e concentrada nas áreas da indústria, agropecuária, comércio e serviços, com importante contribuição para as exportações em âmbito nacional.

Realizada a revisão da literatura nacional e internacional, para a apresentação da base teórica em especial do SRI, o método empregado foi a análise descritiva da Pesquisa de Inovação (PINTEC), realizada pelo Instituto Brasileiro de Geografia e Estatística (IBGE). Pela disponibilidade de dados foi utilizado as pesquisas dos anos de 2000, 2003, 2005, 2008, 2011 e 2014, retirados no site do referido órgão. A análise de variáveis tem como objetivo apoiar os resultados que esteja vinculado a visão das empresas sobre o arranjo institucional e como elas se relacionam como organizações externas, em especial Universidade e Governo, e a parceria das três organizações para o desenvolvimento de seus respectivos Sls estaduais.

A PINTEC apresenta uma lista de dados que informam os principais problemas e obstáculos encontrados pelas empresas para a realização e para a implantação de atividades de inovação, composta de fatores de natureza econômica (custos, riscos, fontes de financiamento apropriadas e força de trabalho qualificada), problemas internos à empresa (rigidez organizacional), problemas com os seus SI estaduais (cooperação com outras empresas/instituições). Estes itens são investigados nas edições da PINTEC, proporcionando a oportunidade de identificar quais são os problemas, obstáculos e as relações sinérgicas de alta e baixa relevância, de acordo com a análise das firmas, para o desenvolvimento de suas atividades inovadoras e seus reflexos no SRI. A abordagem da pesquisa foi quantitativa, com análise por meio da estatística descritiva, apresentando-se as quantidades de empresas que participaram da pesquisa, total de empresas que realizaram inovações a nível estadual.

\subsection{Resultados da Pesquisa}

Apresenta-se nesta seção os resultados para as variáveis coletadas, além do debate com trabalhos anteriores, e com análise da revisão teórica já feita neste trabalho. Espera-se que durante o período analisado, de acordo com a literatura estudada, as variáveis que indiquem expertise e a implantação de atividades de inovação das firmas possam esta relacionadas com a variação dos indicadores do SRI. Assim, se os resultados sugerirem melhoras das competências 
das firmas espera-se que esse resultado esteja relacionado ao fortalecimento dos relacionamentos entre U-I-G, e a um possível processo de ciclo virtuoso em ambos estados.

Gráfico 1- Total de Empresas Pesquisadas, Tipo de Inovação e o Alcance das Atividades de P\&D Implementadas.
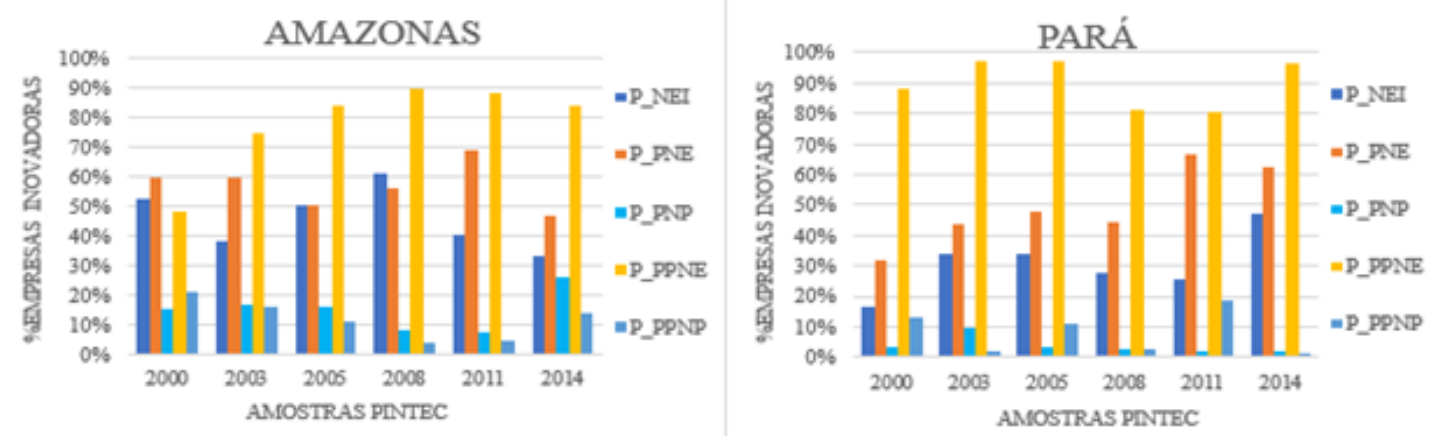

P_NEI: Número de empresas/ número de empresas que implementaram inovação

P_PNE: Produtos novos para empresas/ número de empresas que implementaram inovação

P_PNP: Produtos novos para o país/ número de empresas que implementaram inovação

P_PPNE: Processos novos para empresas/ número de empresas que implementaram inovação

P PPNP: Processos novos para o país/ número de empresas que implementaram inovação

Fonte: Elaborada pelo autor, dados retirados da PINTEC/IBGE.

No gráfico 1, analisa-se a parcela das empresas que implementaram atividade de P\&D do total de empresas pesquisada (P_NEI), notou-se qualidade nos indicadores do estado do Amazonas. Uma parcela da sua produção é voltada para incrementar as inovações em produtos para ao país (P_PNP), o que pode ser explicado pelo PIM. Já as inovações em processos (P_PPNP), não apresentam a mesmas expressividades para o país. No estado do Para há baixa contribuição para as atividades inovadoras em âmbito nacional tanto em inovações em produto quanto as inovações em processos (P_PNP e P_PPNP). Relacionando a inovação em processos para empresas (P_PPNE), que está relacionada nos métodos de produção ou distribuição das empresas (OCDE, 2015), ambos os estados apresentam iguais características.

O gráfico 2 apresenta dados referente as principais atividades implementadas, demonstrando qual a relevância de agregar competências a firma por meio dos relacionamentos com agentes externos, e também a importância de manter uma estrutura interna de P\&D e desta forma melhorar a competitividade por meio da aquisição de know how (CASSIOLATO e LASTRES, 2000). Os dados sugerem que as empresas dos estados do PA e AM, apresentam baixa relevância para a atividades externa (P_AEP_DB) e interna (P_AIP_DB) de P\&D e têm suas estratégias voltadas para aquisição de maquinário ( $\left.P \_A M E A\right)$, indicando que as empresas não internalizam conhecimentos externos, somente há aquisição de conhecimento codificado afetando as formas dinâmicas de aprendizado (WOLF, S/D). Assim, as empresas desses estados podem apresentar dificuldades em absorver novas informação e aplicá-las em bens e serviços comercializáveis (COHEN e LEVINTHAL, 1990), corroborando como os dados analisados no gráfico 1, a relevância 
assistida na aquisição de máquinas e equipamento demonstrando uma estratégia passiva (CASSIOLATO e LASTRES, 2000; NEGRI, 2015). Ainda comparando os dois gráficos, o estado do Amazonas apresenta tendência ao perfil de inovação intramuro e importador de tecnologia, pois o bom desempenho em inovações em produtos para o país (P_PNP) e acompanhado por baixo desempenho no P\&D interno e externo.

Gráfico 2- Estratégias e Rotinas das Firmas
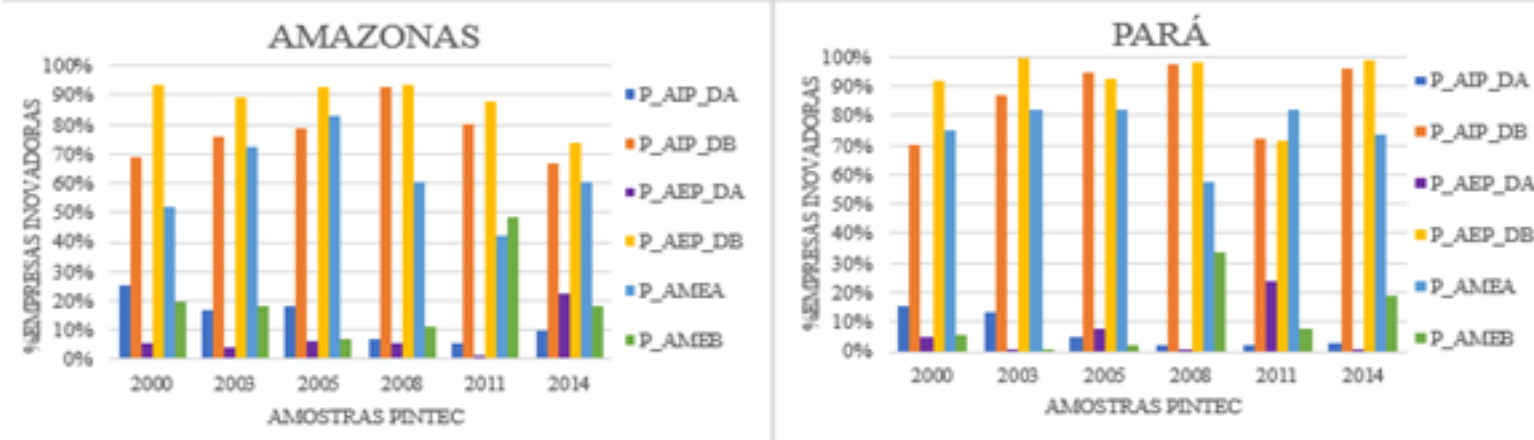

P_AIP_DA: Atividade interna de P\&D alta/ número de empresas inovadoras

P_AIP_DB: atividade interna de P\&D baixa/ número de empresas inovadoras

P_AEP_DA: atividade externa de P\&D alta/ número de empresas inovadoras

P_AEP_DB: atividade externa de P\&D baixa/ número de empresas inovadoras

P AMEA: aquisição máquinas e equipamentos alta/ número de empresas inovadoras

P_AMEB: aquisição máquinas e equipamentos baixa/ número de empresas inovadoras

Fonte: Elaborada pelo autor, dados retirados da PINTEC/IBGE.

$\mathrm{O}$ gráfico 3 demonstra o relacionamento com os outros dois agentes do modelo $\mathrm{HT}$, universidade e governo, demonstrando o compartilhamento de competências no processo de inovação regional (WOLF, S/D; COHEN e LEVINTHAL, 1990; AUXILIAR, 2010; ETKOWITZ e ZHOU, 2017). Neste gráfico um importante dado é o baixo reconhecimento da universidade como fonte principal de informação (P-FPIU) em todos os agregados, fato que influência negativamente na relação de cooperação I-U, e afeta o fluxo de conhecimento entre os diferentes processos da aprendizagem (WOLF, S/D; ETKOWITZ, 2009).

Gráfico 3 - Fonte de Informação e a Interface com Governo e Universidade

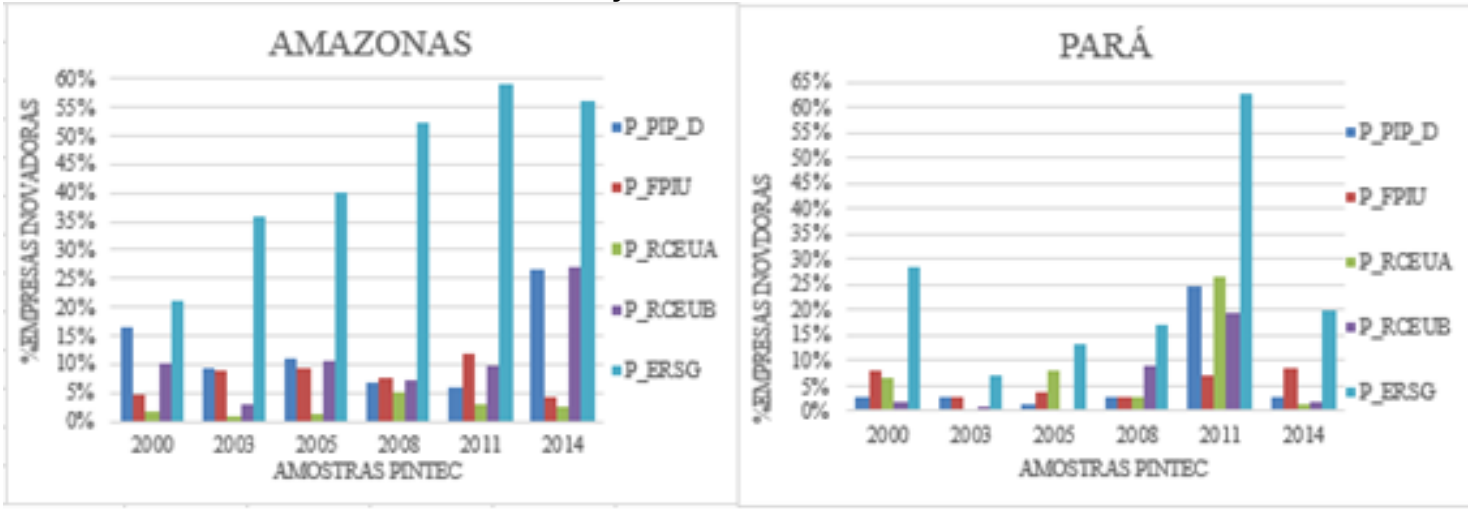

P PIP D: Fonte interna de informação P\&D interna / número de empresas inovadoras

P_FPIU: Fonte de informação universidade / número de empresas inovadoras

P_RCEUA: Relação de cooperação empresa universidade alta / número de empresas inovadoras

P_RCEUB: Relação de cooperação empresa universidade baixa / número de empresas inovadoras

P_ERSG: Empresa receberam suporte do governo/ número de empresas inovadoras 
Fonte: Elaborada pelo autor, dados retirados da PINTEC/IBGE.

O apoio do governo (P_ERSG), por meio da política de incentivos de financeiros e fiscais tem se constituído um importante e crescente mecanismo de auxílio às empresas que inovam (CASSIOLATO et al, 2015; MIRANDA e ZUCOLOTA, 2016), como esperado, no estado do Amazonas em virtude do PIM. No estado do Pará o suporte do governo (P_ERSG) apresenta efeito cíclico, podendo ser reflexo na condição do governo em manter essa política ou a interferência de mudanças políticas. Esse estado apresenta ainda, melhora nas relações com a universidade (P_RCEUB e P_RCEUA), até 2011, nessa amostra cerca de $25 \%$ das empresas reconhecia na universidade uma importante agente para cooperação em atividades de inovação, ocorrendo com queda acentuada na amostra de 2014.

O gráfico 4 apresenta a análise das empresas que não inovaram por alguma relevante fragilidade no quadro institucional e também as firmas inovadoras que durante o processo de inovação encontraram dificuldades. Tendo o objetivo de comparar as dificuldades e semelhanças nas incertezas para as empresas inovarem, que pode ser reflexo de falhas no arranjo institucional, que inibi as empresas inovarem (ETKOWITZ, 2009). Os dados do estado do Amazonas sugerem incerteza entre empresas inovadoras e não inovadoras. Podem se observa diversidade entre as empresas, apresentando patamares muito próximo porém em movimento cíclico e opostos, ou seja, quando as empresas inovadoras analisam como altos (NREE_A), (NECI_A), (NEFF_A) e (NFPQ_A) com os gráficos em movimento de crescimento, pode se observa os gráficos das empresas não inovadoras apresentando queda no número de empresas que afirmaram ser altos as fragilidades do ambiente institucional. Os gráficos do estado do Pará não apresentam essa característica, a instabilidade no ambiente institucional afeta de forma homogenia a estratégia entre inovadoras e não inovadoras. 
Gráfico 4- Fragilidades Para a Inovação nas Firmas Inovadoras e Não Inovadoras.

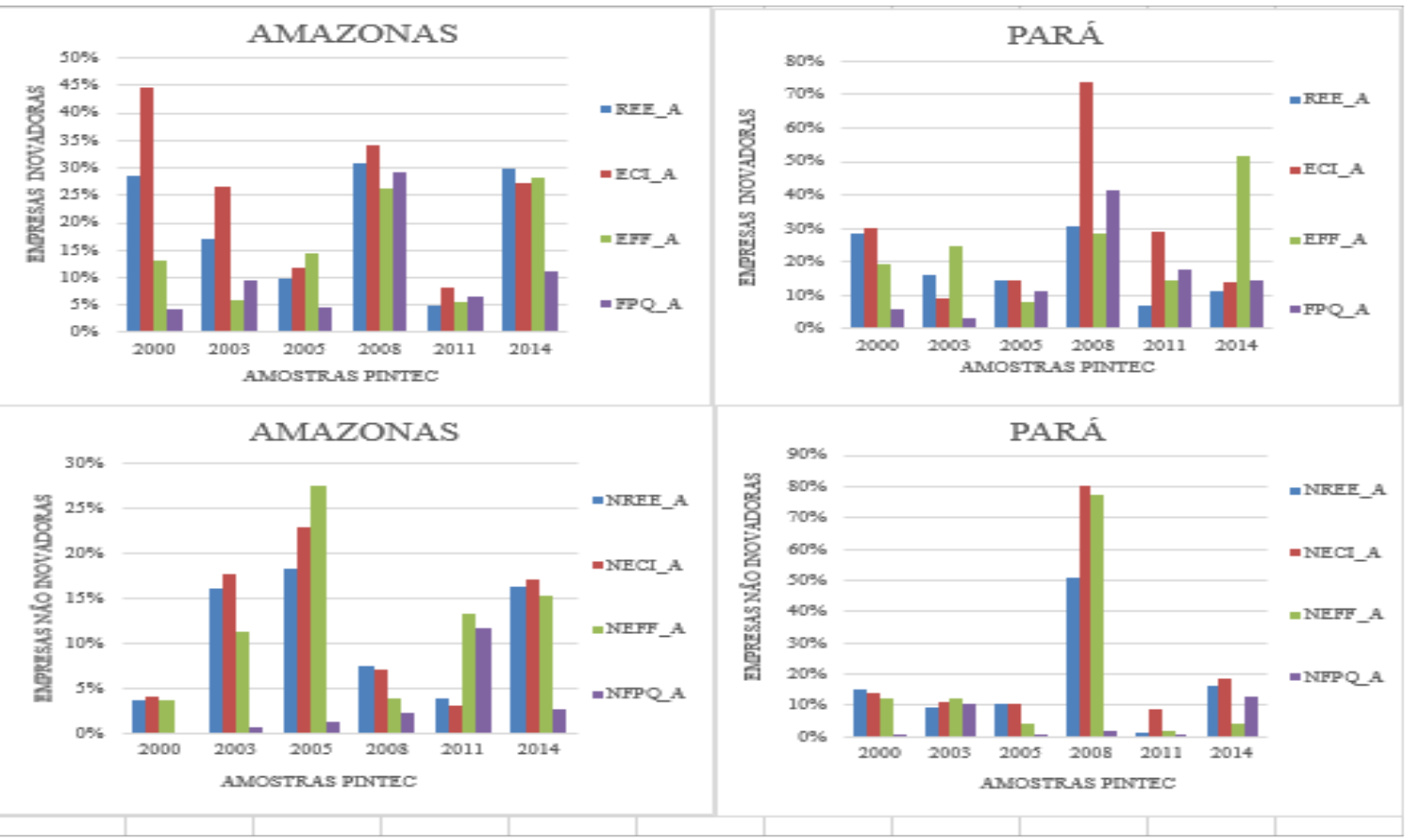

NREE_A: Riscos econômicos excessivos alto (antes de inovar) / número de empresas não inovadoras NECI_A: Elevados custos da inovação alto (antes de inovar) / número de empresas não inovadoras NEFF_A: Escassez de fontes de financiamento alto (antes de inovar) / número de empresas não inovadoras NFPQ $\urcorner$ A: Falta de pessoal qualificado alto (antes de inovar) / número de empresas não inovadoras REE_A: Riscos econômicos excessivos alto (atividades implementadas) / número de empresas inovadoras ECl_A: Elevados custos da inovação alto (atividades implementadas) / número de empresas inovadoras EFF_A: Escassez de fontes de financiamento alto (atividades implementadas) / número de empresas inovadoras FPQ_A: Falta de pessoal qualificado alto (atividades implementadas) / número de empresas inovadoras Fonte: Elaborada pelo autor, dados retirados da PINTEC/IBGE.

Dois pontos chamam atenção no gráfico 4, que são os resultados das variáveis (NEFF_A) e (NFPQ_A). A primeira é o suporte de financiamento do governo visualizado no gráfico 3 deve ser completado, pois segundo a visão das empresas, há deficiência nas fontes de financiamento adequada para inovação. Já na análise da mão de obra qualificada (NFPQ_A), apresenta uma relevância na necessidade de qualificação da mão de obra, pois é de se esperar que nas empresas não inovadoras há baixa demandam para esses profissionais (WOLF, S/D; COHEN e LEVINTHAL, 1990), porém a mão de obra qualificada apresenta ser uma fragilidade pelas empresas inovadoras, ou seja, quando incorporada no processo produtivo se mostra como uma dificuldade para o processo de inovação. Porém há incoerência com as informações já analisadas, pois as empresas apresentam um alta relevância para a aquisição de máquinas e equipamentos no gráfico 1 complementar a baixa relevância das atividades internas de P\&D no gráfico 2, necessitando de uma análise mais cuidadosa, que será feito analisando se pode haver um perfil passivo ou pró ativo nessas empresas. 
Gráfico 5- Passividade nas Firmas que Não Inovam

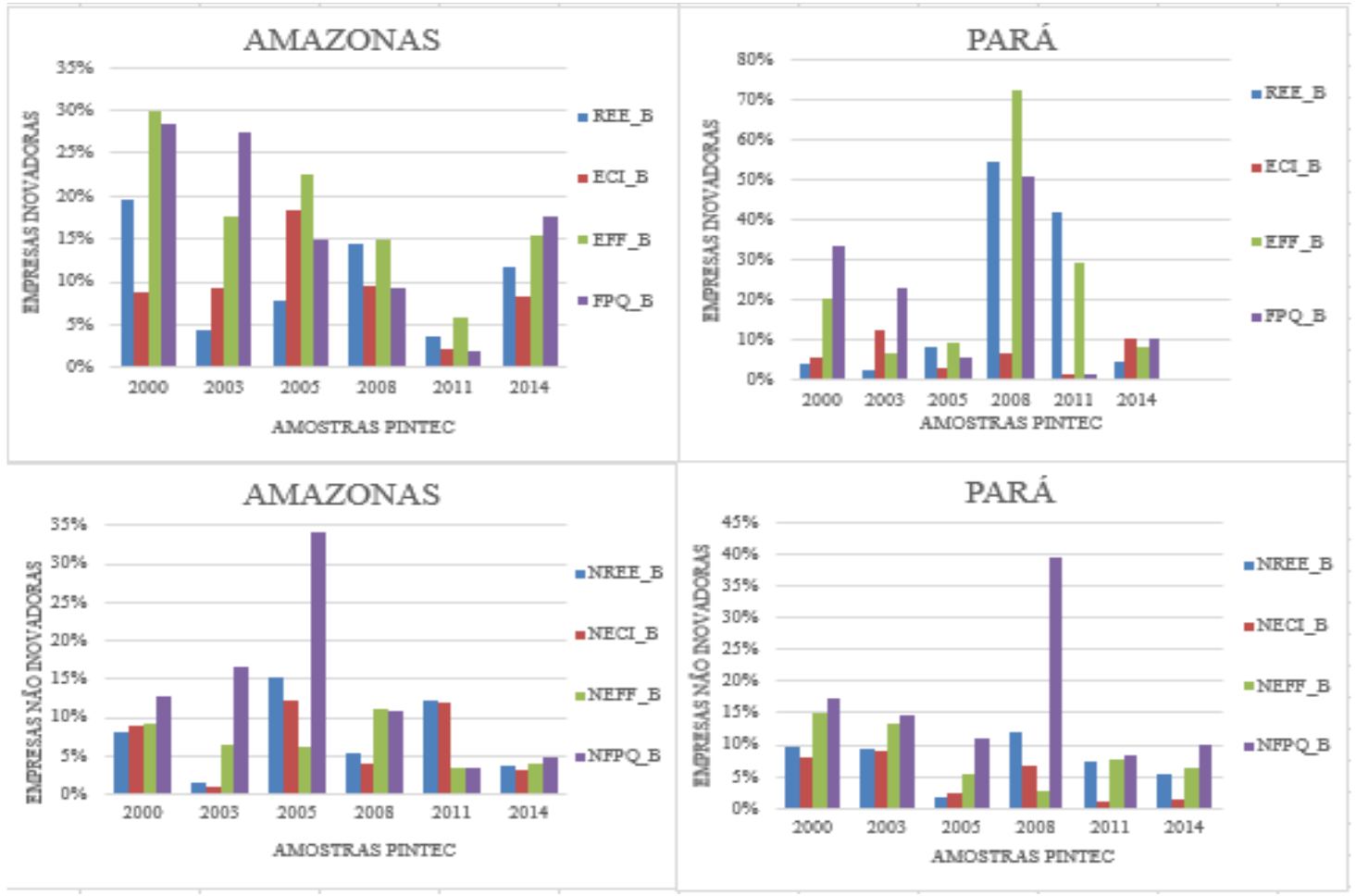

NREE_B: Riscos econômicos excessivos baixo (antes de inovar) / número de empresas não inovadoras $\mathrm{NECl} \mathrm{B}$ : Elevados custos da inovação baixo (antes de inovar) / número de empresas não inovadoras NEFF_B: Escassez de fontes de financiamento baixo (antes de inovar) / número de empresas não inovadoras NFPQ_B: Falta de pessoal qualificado baixo (antes de inovar) / número de empresas não inovadoras REE_B: Riscos econômicos excessivos baixo (atividades implementadas) / número de empresas inovadoras ECI_B: Elevados custos da inovação baixo (atividades implementadas) / número de empresas inovadoras EFF_B: Escassez de fontes de financiamento baixo (atividades implementadas) / número de empresas inovadoras FPQ_B: Falta de pessoal qualificado baixo (atividades implementadas) / número de empresas inovadoras Fonte: Elaborada pelo autor, dados retirados da PINTEC/IBGE.

O gráfico 5 tem como objetivo analisar o nível de passividade das estratégias das firmas inovadoras e não inovadoras e a relevância do quadro institucional para a decisão de não inovar. Com a revisão da literatura, em especial sobre Hélice Tríplice, dos gráficos anteriores e com intuito de uma aproximação da realidade foi relacionados os dados dos gráficos acima. Neste gráfico, assim como o gráfico 4, há uma comparação entre firmas inovadoras e não inovadoras, sendo que os resultados sugerem que nos estados do Pará e Amazonas a qualificação da mão de obra (NFPQ_B) e o obstáculo com menor relevância para as empresas não inovadoras e inovadoras, porém com movimento declinante durante a série. Há de se considerar que as firmas não inovadoras teriam a percepção mais branda sobre as fragilidades do ambiente institucional, por isso e importante saber se a decisão de não inovar e uma estratégia interna da empresa, levando em consideração sua competência e know how ou é efeito da fragilidade do ambiente institucional. Dessa forma, é preciso investigar se há uma cultura de inovação emergente com reflexo nas

\footnotetext{
${ }^{5} \mathrm{O}$ número de empresas não inovadores é resultado do número de empresas entrevistadas subtraído o número de empresa que implementaram atividades de inovação.
} 
competências das firmas, o que será feito analisando a frequência e 0 tipo das atividades implementadas e também se essas atividades estão resultando em novos produtos.

Gráfico 6: Resultados das Vendas e Frequência das Atividades de P\&D - Amazonas

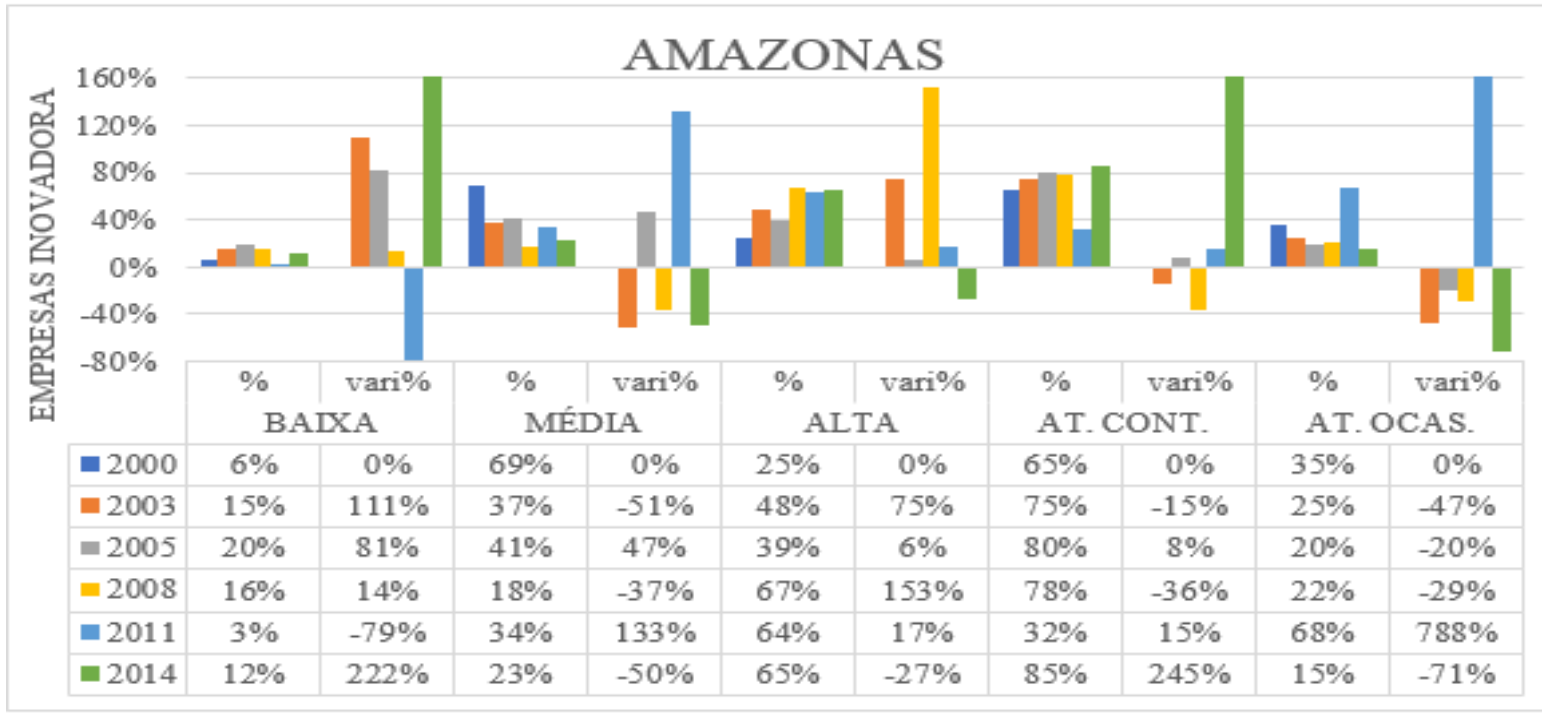

\%: Porcentagem das empresas inovadoras que participam da variável.

vari\%: Variação percentual, de um ano para outro, do número de empresas relacionada a variável. vari $^{\%}=\left(\frac{\text { vari }_{1}-\text { vari }_{0}}{\text { vari }_{0}}\right) * 100 \%$

BAIXA: Empresas que a implantação de produtos novos representa $10 \%$ das vendas.

MÉDIA: Empresas que a implantação de produtos novos representa acima de $10 \%$ e abaixo de $40 \%$ das vendas.

ALTA: Empresas que a implantação de produtos novos representa acima de $40 \%$ das vendas.

AT. CONT.: Empresas que implementam atividades de P\&D de maneira continua.

AT. OCAS.: Empresas que implementam atividades de P\&D ocasionalmente.

Fonte: Elaborada pelo autor, dados retirados da PINTEC/IBGE.

No gráfico 6 nota-se uma estabilidade na parcela que representam 10\% das vendas e uma redução da porcentagem de empresas da camada MÉDIA e um efeito inverso na parcela das empresas que têm produtos novos com maior participação nas vendas. Nota-se, de maneira mais destacada, variações negativas da participação das empresas inovadoras na faixa mediana de vendas. Este cenário de vendas é acompanhado de uma parcela menor, e com variações negativas, das empresas que implementam atividades de P\&D de maneira ocasional e uma parcela significativa, cerca de $70 \%$ durante o período afirma implementam atividade de P\&D de maneira continua.

No gráfico 7, relacionado ao estado do Pará, nota-se também estabilidade na parcela que representam $10 \%$ das vendas, e uma tendência de aumento da porcentagem de empresas da camada seguinte. Observa- se também, efeito inverso na parcela das empresas da camada ALTA, as quais têm produtos novos com maior participação nas vendas. No que se relaciona a variação do número de empresas, há movimento contrário do Amazonas, com variação positivas na faixa mediana de empresas inovadoras e oscilação na escolhas das empresas entre P\&D ocasional e continuo, acompanhado de variações negativas nas ultimas amostras de empresas que implementam atividades de P\&D de maneira ocasional. 
Gráfico 7: Resultados das Vendas e Frequência das Atividades de P\&D- Pará

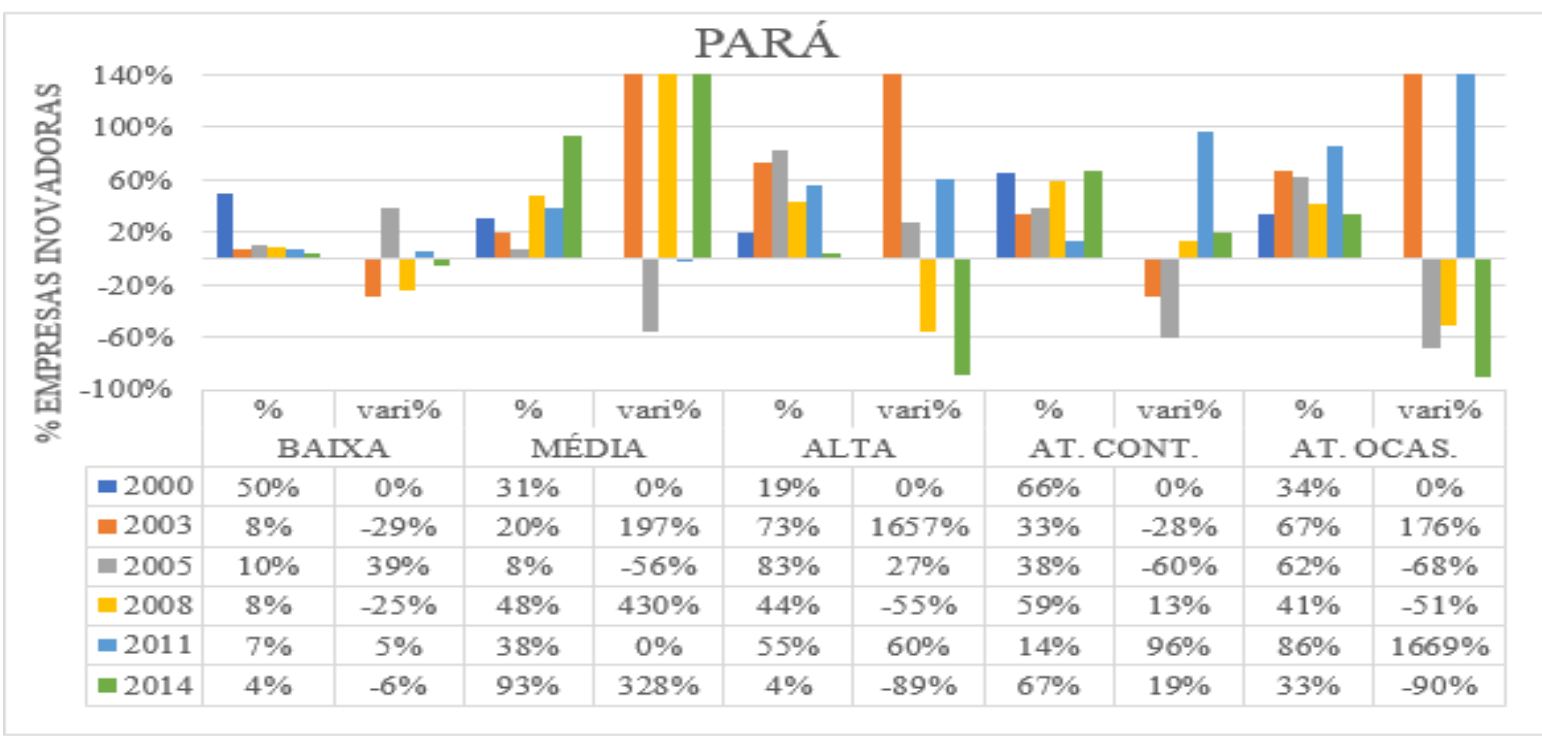

\%: Porcentagem das empresas inovadoras que participam da variável.

vari\%: Variação percentual, de um ano para outro, do número de empresas relacionada a variável. vari $_{\%}=\left(\frac{\text { vari }_{1}-\text { vari }_{0}}{\text { vari }_{0}}\right) * 100 \%$

BAIXA: Empresas que a implantação de produtos novos representa $10 \%$ das vendas.

MÉDIA: Empresas que a implantação de produtos novos representa acima de $10 \%$ e abaixo de $40 \%$ das vendas.

ALTA: Empresas que a implantação de produtos novos representa acima de $40 \%$ das vendas.

AT. CONT.: Empresas que implementam atividades de P\&D de maneira continua.

AT. OCAS.: Empresas que implementam atividades de P\&D ocasionalmente.

Fonte: Elaborada pelo autor, dados retirados da PINTEC/IBGE.

A literatura que referente aos SRIs condiciona que o desenvolvimento de cada região se caracteriza por condições próprias de cada SRI emergente, sendo a sinergia entre atores e estruturas institucional para transformar essas as condições em vantagem regional (ASHEIM, 2019). Assim, como a literatura os dados coletados mostram dois estados configuram-se sistemas de inovação distintos em suas competências e de duas fragilidades, apesar da proximidade geográfica. Os gráficos apresentados sugerem relações conflituosas no ambiente institucional e um resultado positivo nos números de empresas que implementaram produtos novos comercializados nos anos de 2000 a 2014.

\subsection{CONSIDERAÇÕES FINAIS}

A partir da discussão sobre Sistemas de Regional de Inovação e com a contribuição do modelo Hélice Tríplice, que reforçam as tendências diferentes entre as regiões, analisou-se as desigualdades do Sistemas de inovação do estados do Pará e Amazonas, e como sua eficiência tecnológica é resultado do ambiente institucional, o que de fato os dados sugerem ser uma tendência no Brasil. Observou-se que houve sucesso na produção de inovações referente a produtos novos comercializáveis, porém, faz se necessário a agregar mais variáveis, em especial das outras duas organizações citadas, Universidade e Governo,. 
Compreendo os limites deste trabalho e da metodologia utilizada, mas tendo o objetivo de construir cenários possíveis para outros estudos mais focados nas organizações regionais e como ferramentas de análise mais robusta, este trabalho necessita de continuidade. Assim, desdobram-se alguns dos objetivos centrais e articulados para futuros projetos de pesquisa reconheço a necessidade de efetuar discussões mais aprofundadas sobre o estímulo doa relacionamentos U-I-G, focalizando o ponto de vista do desenvolvimento local; e, em segundo lugar, avaliar os impactos das recentes transformações no SI e seu reflexos na eficiência produtiva, dado que as fragilidades no ambientes institucional nos dois estados, sobretudo o estudo da participação de cada um das organizações estudadas e o resultado sinérgico na formação dos espaços de competências para assim, debatendo suas capacidades e habilidades e deficiências, entendendo como relevante a construção dessa análise para a configuração de novas políticas, fortalecer o SRI e criar novas possibilidades para a interação entre base científica e desenvolvimento industrial.

\section{REFERÊNCIAS BIBLIOGRÁFICAS}

ACEMOGLU, D.; JOHNSON, S.; ROBINSON, J. Institutions as the fundamental cause of longrun growth. Cambridge, MA, National Bureau of Economic Research, 2004. Working Paper 10481.

ARCURI, M. Políticas de CT\&I e Financiamento Público à infraestrutura de C\&T: comparações internacionais e mapeamento da infraestrutura nacional. In: DE NEGRI, Fernanda; SQUEFF, Flávia de H.S. (Org.). Sistemas Setoriais de Inovação e Infraestrutura de Pesquisa no Brasil. Brasília: IPEA, 2016.

ARTHUR, W.B. Competing Technologies, Increasing Returns, and Lock-In by Historical Events.The Economic Journal, vol. 99, no. 394, 1989, pp. 116-131.

ASHEIM, B.; HERSTAD, S. Regional Innovation Systems, Varieties of Capitalism and NonLocal Relations: Challenges from the Globalising Economy. 10.1007/1-4020-3679-5_8. 2005.

AUXILIAR, M. J. P. DO R. M. 0 modelo triple Helix as relações entre a Universidade de Coimbra e a indústria. Coimbra, 2010.

BRASIL. IBGE. Pesquisa industrial de inovação tecnológica / IBGE, Coordenação de Indústria. Local: Rio de Janeiro: ed. IBGE, 2004.

BRESCHI, S.; MALERBA, F. Sectoral Innovation Systems: Technological Regimes, Schumpeterian Dynamics, and Spatial Boundaries", in C Edquist (ed.), Systems Of Innovation: Technologies, Institutions, And Organizations, Pinter, London s. 130-56.1997.

BRUSCHI P.L, MACHADO S.A.G. Estratégias de inovação sob a perspectiva da ResourcedBased View: análise e evidências em empresas de base tecnológica. Prod., São Carlos, v. 21, n. 1, p. 125-141, 2014.

BUENO, N. P. W. Brian Arthur. The Nature of Technology - What it is and how it evolves. Revista Brasileira de Inovação, 8(2), 535-540. (2010). CARNEIRO, R. Impasses do desenvolvimento brasileiro: a questão produtiva. Campinas: IE/Unicamp. Texto para discussão, n.153).

CARLSSON, B.; JACOBSSON, S.; HOLMÉN, M.; RICKNE, A. (2002). Innovation Systems: Analytical And Methodological Issues. Research Policy. 31. 233-245. 10.1016/S00487333(01)00138-X, 2002. 
CASSIOLATO, José Eduardo. 0 foco em Arranjo s Produtivos e inovativos locais de micro e pequenas empresas. In: CASSIOLATO, José Eduardo; LASTRES, Helena Maria Martins; MACIEL Maria Lucia. (orgs.) Pequena Empresa: cooperação e desenvolvimento local. Rio de Janeiro: Relume Dumará, 2003.

CASSIOLATO, J. E.; SZAPIRO, M.; LASTRES, H. H. H. Dilemas e perspectivas da Política de Inovação. São Paulo: FGV, 2015.

CASSIOLATO, J. E.; LASTRES, H. M. M. Local Systems of Innovation in Mercosur Facing the Challenges of the 1990s. Local systems of innovation in Mercosur countries. Industry and innovation, 7(1), 33-53. (2000).

COASE, R. H. The Nature of the Firm. 1937. In: Economica, New Series. Inglaterra:The London School of Economics and Political Science, v.4, n. 16, p. 386-405, nov. 1937.

COASE, R. H.The Institutional Structure of Production n: Claude Ménard and Mary M. Shirley (Editors). Handbook of New Institutional Economics. Springer-Verlag Berlin Heidelberg, 2008. p.31-39.

CONTI, S. Espaço global versus espaço local: Perspectiva sistêmica do desenvolvimento local. In DINIZ, C. C; LEMOS, M. Economia e território, 1st ed., Cedeplar, Universidade Federal de Minas Gerais, (2005).

COOKE, P.; BOEKHOLT, P.; SCHALL, N.; SCHIENSTOCK, G. (1996). REGIONAL

INNOVATION SYSTEMS: CONCEPTS, ANALYSIS AND TYPOLOGY Enter title. 1996.

CURADO, Marcelo. Industrialização e desenvolvimento: uma análise do pensamento econômico brasileiro. Econ. soc., Campinas, v. 22, n. 3, p. 609-640, Dec. 2013.

DE NEGRI, F.; SQUEFF, F. H. S. Sistemas setoriais de inovação e infraestrutura de pesquisa no Brasil, Brasília: Ipea, 2016

DINIZ, C. C; LEMOS, M. Economia e território, 1st ed., Cedeplar, Universidade Federal de Minas Gerais, (2005).

DOLOREUX D. "Regional Innovation Systems in Canada: A Comparative Study," Regional Studies, Taylor \& Francis Journals, vol. 38(5), pages 479-492. 2004.

DOLOREUX, D; PARTO, S. Regional innovation systems: Current discourse and unresolved issues, Technology in Society, Volume 27, Issue 2,2005.

DOSI, G. Mudança técnica e transformação industrial: a teoria e uma aplicação à indústria dos semicondutores. Campinas: Editora UNICAMP, 2005.

DUNHAM, F.; BOMTEMPO, J.; FLECK, D.A Estruturação do Sistema de Produção e Inovação Sucroalcooleiro como Base para o Proálcool. Revista Brasileira de Inovação, VL - 10, 2011. EDQUIST, C. Systems of Innovation: Perspectives and Challenges. The Oxford Handbook of Innovation, 2006.

ETZKOWITZ, H., \& LEYDESDORFF, L. (1997). Universities and the global knowledge economy: a triple helix of university-industry-government relations / edited by Henry Etzkowitz and Loet Leydesdorff. Continuum, London. Science, Technology and the International Political $\begin{array}{llll}\text { Economy } & \text { Series, } & \text { Retrieved } & \text { from }\end{array}$ http://www.lavoisier.fr/livre/notice.asp?id=OS3WXKAAXL2OWP

ETZKOWITZ, H; Hélice Tríplice: Universidade-Indústria-Governo inovação em movimento. Porto Alegre: Editora EdiPUCRS, 2009.

ETZKOWITZ, H.; RANGA, M. A Triple Helix System for Knowledge-based Regional Development: From "Spheres" to "Spaces." VIII Triple Helix Conference, 1-29. 2010.

ETZKOWITZ, H; ZHOU, C. Hélice Tríplice: inovação e empreendedorismo universidadeindústria-governo. Estud. av., São Paulo, v. 31, n. 90, p. 23-48, May 2017.

FARINA, E.; AZEVEDO, P.; SAES, M. Competitividade: mercado, estado e organizações. São Paulo: Singular, 1997. p. 29-109. 
FERRAZ, J.; KUPFER, D.; HAGUENAUER, L. MADE IN BRAZIL: Desafios competitivos para a indústria, Rio de janeiro: Campus, 1995.

FIANI, R. Cooperação e conflito: instituições e desenvolvimento econômico. Rio de Janeiro: Elsevier, 2011.

FREEMAN, C.; SOETE, L. A economia da inovação industrial. Campinas: Editora da Unicamp, 2008.

FREEMAN, Chris. 1995. The 'National System of Innovation' in historical perspective. Cambridge Journal of Economics, 1995, v. 19, pp. 5-24.

HERSTAD, S. Regional Innovation Systems, Varieties of Capitalism and Non-Local Relations: Challenges from the Globalising Economy. 10.1007/1-4020-3679-5_8.).2003.

LASTRES, Helena M. M. Informação e conhecimento na nova ordem mundial. Ci. Inf., Brasília, v. 28, n. 1, p. 72-78, jan. 1999.

LASTRES, H.M.M. e ALBAGLI, S. Informação e globalização na era do conhecimento. São Paulo em pespectiva, pág. 60-66, 2002.

LEE. K.; MALERBA, F. Catch-up cycles and changes in industrial leadership: Windows of opportunity and responses of firms and countries in the evolution of sectoral systems, Research Policy, 46, (2), 338-351, 2017.

LUNDVALL, B. Innovation as an interactive process: from user-producer interaction to the national system of innovation. In: DOSI, G., et alii (eds.). Technical change and economic theory. Pinter Publishers, 1988.LUNDVALL, B.A. National systems of innovation: towards a theory of innovation and interactive learning. Londres, Pinter ed. 1992.

MALERBA, F. Sectoral systems of innovation and production. Research Policy, 31, (2), 247264, 2002.

MIRANDA, P.; ZUCOLOTO, G. A presença de conhecimento com perfil inovador nas infraestruturas científicas e tecnológicas no brasil. In: DE NEGRI, Fernanda; SQUEFF, Flávia de H.S. (Org.). Sistemas Setoriais de Inovação e Infraestrutura de Pesquisa no Brasil. Brasília: IPEA, 2016.

NELSON, R.R. e Winter, S.G. Uma teoria evolucionária da mudança econômica. Campinas: Editora Unicamp, 2005.

NORTH, D. C. Institutions, institutional change and economic performance. Cambridge: Cambridge University Press, 1990

NORTH, Douglass C. Institutions and the performance of economies over time. In: Claude Ménard and Mary M. Shirley (Editors). Handbook of New Institutional Economics. Springer-Verlag Berlin Heidelberg, 2008. p.21-30.

MEYER, John W., and Brian Rowan. "Institutionalized Organizations: Formal Structure as Myth and Ceremony." American Journal of Sociology, vol. 83, no. 2, 1977, pp. 340-363. JSTOR, www.jstor.org/stable/2778293.

PAIVA, M.; CUNHA, G.; JUNIOR, C.; CONSTANTINO, M. Inovação e os efeitos sobre a dinâmica de mercado: uma síntese teórica de Smith e Schumpeter. Interações (Campo Grande).2018.

RAPINI, M.S.; SUZIGAN, W.A contribuição das universidades e institutos de pesquisa para o sistema de inovação brasileiro. XXXVII Encontro Nacional de Economia, 2009, Foz do Iguaçu. ROSENBERG, N. Inside the Black Box: Technology and Economics (1982). University of Illinois at Urbana-Champaign's Academy for Entrepreneurial Leadership Historical Research Reference in Entrepreneurship. ROSENBERG, N. Por dentro da caixa preta. Clássicos da Inovação. Ed. Unicamp. Campinas c1983, 2009.

SCHUMPETER, J. A. Capitalismo, socialismo e democracia. Rio de Janeiro: Zahar, 1984.

SCHUMPETER, J. A. Teoria do desenvolvimento econômico: uma investigação sobre lucros, capital, crédito, juro e o ciclo econômico. Traduzido por Maria Sílvia Possas. 3. ed. São Paulo: Nova Cultural, 1988. 
STORPER, M. (1997). The regional world: territorial development in a global economy. Nova York, Guilford Press. STORPER, M. e VENABLES, A. J. (2004). Buzz: face-to-face contact and the urban economy. Journal of economic geography, v. 4, n. 4, pp. 351-370

SUZIGAN, W. e ALBUQUERQUE, E. da M. A interação entre universidades e empresas em perspectiva histórica no Brasil. UFMG/CEDEPLAR, Texto para discussão, 329, 2008.

WILLIAMSON, O. E. Transaction Cost Economics. In: Claude Ménard and Mary M. Shirley (Editors). Handbook of New Institutional Economics. Springer-Verlag Berlin Heidelberg, 2008. p.41-68.

WOLF, D. A. Globalization, information and communication technologies and local and regional systems of innovation. Department of Political Science. University of Toronto, Texts for Discussion, s/d, $20 \mathrm{p}$.

Recebido em Janeiro de 2020

Aceito em Agosto de 2020.

\section{RESUMO}

A literatura direciona a inovação como resultado de ambiente favorável capaz de mobilizar diferentes agentes com contribuições multidisciplinares que fortaleçam uma cultura inovadora nas firmas locais. $O$ presente artigo aborda a literatura existente sobre Sistemas de Inovação e os seus desdobramentos com o objetivo de entender a relação entre 0 ambiente interno das firmas e o seu relacionamento com outras organizações nos estados do Amazonas e Pará. Foram extraídos dados da PINTEC, com o intuito de estudar as parcerias locais, rotinas organizacionais, padrões diferenciados de esforços tecnológicos e obstáculo reconhecidos por essas empresas. As pesquisas são dos anos de 2000, 2003, 2005, 2009, 2011 e 2014. Como resultado observou-se que há melhora no desempenho das firmas inovadoras, ainda que o ambiente institucional apresente fragilidades e pouca interação nas relações entre Universidade-Governo-Indústria.

Palavras-chave: Inovação. Sistemas Nacionais. Sistemas Regionais. Hélice Tríplice.

ABSTRACT

The literature directs innovation as a result of a favorable environment capable of mobilizing different agents with multidisciplinary contributions that strengthen an innovative culture in local firms. This article discusses the existing literature on Innovation Systems and its developments in order to understand the relationship between the internal environment of firms and their relationship with other organizations in the states of Amazonas and Pará. Data were extracted from PINTEC, with the in order to study local partnerships, organizational routines, differentiated patterns of technological efforts and obstacles recognized by these companies. The surveys are from the years 2000, 2003, 2005, 2009, 2011 and 2014. As a result, it was observed that there is an improvement in the performance of innovative firms, even though the institutional environment presents weaknesses and little interaction in the relations between UniversityGovernment-Industry.

Keywords: Innovation. National Systems. Regional Systems. Triple Helix. 